\title{
Tolerance to the Herbicide Glufosinate in Transgenic Cranberry (Vaccinium macrocarpon Ait.) and Enhancement of Tolerance in Progeny
}

\author{
Eric L. Zeldin, ${ }^{1}$ Thomas P. Jury, ${ }^{2}$ Rodney A. Serres, ${ }^{3}$ and Brent H. McCown ${ }^{4}$ \\ Department of Horticulture, University of Wisconsin-Madison, Madison, WI 53706
}

\begin{abstract}
ADDITIONAL INDEX WORDS. Liberty herbicide, phosphinothricin, biolistics, genetic engineering, transformation
Abstract. The American cranberry (Vaccinium macrocarpon Ait.) was genetically transformed with the bar gene, conferring tolerance to the phosphinothricin-based herbicide glufosinate. Plants of one 'Pilgrim' transclone grown under greenhouse conditions were significantly injured by foliar treatments of $100 \mathrm{mg} \cdot \mathrm{L}^{-1}$ glufosinate, although the injury was less severe when compared to untransformed plants. However, the same transclone grown outdoors in coldframes survived foliar sprays of $500 \mathrm{mg} \cdot \mathrm{L}^{-1}$ glufosinate and higher, while untransformed plants were killed at $300 \mathrm{mg} \cdot \mathrm{L}^{-1}$. Actively growing shoot tips were the most sensitive part of the plants and at higher dosages of glufosinate, shoot-tip injury was evident on the transclone. Injured transgenic plants quickly regrew new shoots. Shoots of goldenrod (Solidago sp.) and creeping sedge (Carex chordorrhizia), two weeds common to cranberry production areas, were seriously injured or killed at $400 \mathrm{mg} \cdot \mathbf{L}^{-1}$ glufosinate when grown in either the greenhouse or coldframe environment. Stable transmission and expression of herbicide tolerance was observed in both inbred and outcrossed progeny of the above cranberry transclone. Expected segregation ratios were observed in the outcrossed progeny and some outcrossed individuals demonstrated significantly enhanced tolerance over the original transclone, with no tip death at levels up to $8000 \mathrm{mg} \cdot \mathrm{L}^{-1}$. Southern analysis of the original transclone and two progeny selections with enhanced tolerance showed an identical banding pattern, indicating that the difference in tolerance levels was not due to rearrangement of the transgene. The enhanced tolerance of these first generation progeny was retained when second generation selfed progeny were tested.
\end{abstract}

The American cranberry is a low-growing perennial vine, grown commercially in solid stands in beds up to 2 ha in size. Newly planted vines require 3 to 5 years to establish a good cover and to begin producing average yields; however, they may be productive for many decades thereafter. Weed competition can significantly reduce cranberry yields (Dana, 1989; Patten and Wang, 1994), and growers must constantly utilize cultural and chemical measures to control the weeds. Because of the high requirement for water during various phases of production, most cranberry beds are located near major water resources, thus increasing the potential for negative environmental impacts from weed control practices. The use of biorational herbicides that have broad spectrum activity, low toxicity to wildlife, and low half-lives in the soil, combined with cranberry plants genetically modified for tolerance to these herbicides, offers an attractive weed control strategy.

L-Phosphinothricin is a naturally occurring amino acid that is a potent inhibitor of all forms of glutamine synthetase occurring in plants (Leason et al., 1982; Wild and Manderscheid, 1984). Inhibition of glutamine synthetase results in the toxic accumulation of ammonia produced by direct uptake, photorespiration, nitrate reduction, or protein/amino acid metabolism (Wallsgrove et al., 1987; Wild et al., 1987). Tolerance to the herbicide has been

Received for publication 23 Jan. 2002. Accepted for publication 5 Apr. 2002. The Wisconsin Cranberry Board, Inc., Ocean Spray Cranberries, Inc., the Gottschalk Endowment, and the Research Station, College of Agriculture and Life Sciences, UW-Madison supported this research. The authors wish to acknowledge Dave Russell and Mike Peterson, Agracetus Corp., for their assistance with the ACCELL transformation system and PCR/Southern analysis, respectively, and Michell Sass, University of Wisconsin-Madison, for her PCR analyses. The helpful review of the manuscript by Michael Havey and Irwin Goldman was greatly appreciated.

${ }^{1}$ Researcher.

${ }^{2}$ Graduate student.

${ }^{3}$ Postdoctoral fellow; current address: Ocean Spray Cranberries, Inc., 1 Ocean Spray Dr., Lakeville-Middleboro, MA, 02349.

${ }^{4}$ Gottschalk distinguished professor; e-mail bhmccown@facstaff.wisc.edu. obtained in many crops and often employs the resistance gene, bar. Bar was derived from a common soil bacterium Streptomyces hygroscopicus and encodes an enzyme that acetylates phosphinothricin, thus inactivating the herbicidal activity (Thompson et al., 1987).

This paper reports the successful transformation of cranberry with the bar gene. One transclone showed moderate tolerance to the glufosinate (the ammonium salt of phosphinothricin) herbicide Liberty, and some outcrossed progeny showed significantly elevated tolerance over the original transclone, reaching commercially useful levels.

\section{Materials and Methods}

GENETIC TRANSFORMATION OF CRANBERRY WITH THE bar GENE. The transformation protocol was identical to that previously described for the transfer of gus and $b t$ genes into cranberry (Serres et al., 1992). The cultivars 'Stevens' and 'Pilgrim' were used. The construct had a pUC19 plasmid backbone (YanishPerron et al., 1985) and contained the bar gene driven by a cauliflower mosaic virus (CaMV) 35s promoter (Nagy et al., 1985; Odell et al., 1985) containing the alfalfa mosaic virus noncoding leader sequence (Gehrke et al., 1983) 5 ' to the coding sequence and a soybean small subunit gene polyadenylation signal region (Berry-Lowe et al., 1982). The plasmid also contained the aphII gene, driven by the nopaline synthetase promoter, conferring tolerance to the antibiotic kanamycin (McCown et al., 1991).

The presence of the bar gene in the cranberry transformant displaying the best herbicide tolerance was confirmed by polymerase chain reaction (PCR) performed both at the University of Wisconsin (Michell Sass, personal communication) and at Agracetus Corp. (Mike Petersen, personal communication).

In VITRO HERBICIDE TOLERANCE EVALUATION. Putatively transformed shoots were initially selected using kanamycin (Serres et al., 1992), as previous attempts to use phosphinothricin as the 
selective agent were unsuccessful. Selected shoots were multiplied by cutting stem segments and the resulting microshoots were exposed to bialophos (the di-alanine conjugate of phosphinothricin) in an in vitro inhibition assay. Shoot tips $2 \mathrm{~cm}$ long were excised from actively growing shoot cultures and placed vertically to a depth of one node on a medium containing $0.25 \mathrm{mg} \cdot \mathrm{L}^{-1}$ bialophos in $25 \times 95 \mathrm{~mm}$ shell vials capped with Magenta two-way closures. A range of bialophos concentrations had been tested on untransformed shoots, and the $0.25 \mathrm{mg} \cdot \mathrm{L}^{-1}$ level yielded sufficient growth inhibition to allow for selection without overwhelming the shoots. Increase in shoot length and root development were recorded after 5 weeks and a total of six transclones consisting of both 'Stevens' and 'Pilgrim' individuals was selected for further testing.

Plant propagation and growth Conditions. Plants were initially micropropagated (Serres et al., 1993). Microcuttings of transformed and untransformed cranberry were rooted in moistened commercial peat moss in covered plastic trays under continuous cool white fluorescent light $\left(\approx 30 \mathrm{mmol} \cdot \mathrm{m}^{-2} \cdot \mathrm{s}^{-1}\right)$ at $22^{\circ} \mathrm{C}$. The trays were periodically misted with distilled water to keep the microcuttings moist. After 2 weeks, the plants were fertilized with $0.2 \mathrm{~g} \cdot \mathrm{L}^{-1}$ soluble fertilizer (Miracid, 30-10-10) and the trays were slowly vented to allow the plants to acclimate to ambient air. After another week, the plants were transferred to the greenhouse and maintained under $16-\mathrm{h}$ photoperiod (with $200 \mathrm{mmol} \cdot \mathrm{m}^{-2} \cdot \mathrm{s}^{-1}$ supplemental high-pressure sodium lighting) with $20{ }^{\circ} \mathrm{C}$ minimum temperature. Thereafter the plants were fertilized weekly with $1.25 \mathrm{~g} \cdot \mathrm{L}^{-1}$ Miracid. After 6 to 7 weeks, these plants were used as stock plants and tip cuttings $(\approx 10 \mathrm{~cm}$ long) were removed and rooted in moistened peat in $6 \times 6 \times 13 \mathrm{~cm}$ plastic pots (tree bands) in a shaded fog tent in the greenhouse. The timing and handling were otherwise similar to that of micropropagated cuttings, and the resulting plants were equivalent. Plants for initial greenhouse treatments were $\approx 12$ weeks old at the time of treatment.

For coldframe treatments, greenhouse plants were pruned thoroughly in late May or early June and placed outside in open frames. Fertilization was continued as above until terminated in mid-August. The age of the plants at treatment ranged from 16 to 18 weeks, depending on the timing of the treatment.

Plants of goldenrod (Solidago sp.) were originally collected from a young cranberry bed in central Wisconsin. For subsequent propagation, $5 \mathrm{~cm}$ rhizome tips with some roots attached were harvested from existing plants. These were placed in tree bands and otherwise handled the same as the cranberry plants, except that they were only pruned to remove excess growth. The age of these plants at treatment was variable, depending on the timing of cranberry treatments.

Plants of creeping sedge (Carex chordorrhizia) were originally collected from an established cranberry bed in northern Wisconsin. These were propagated by layering. Stolons extending from existing potted plants were bent and buried into new tree bands. When these had rooted, the stems to the parent plants were cut. These plants were otherwise handled the same as the goldenrod plants.

Untransformed control plants were either of the cultivar 'Stevens' or 'Pilgrim', depending on availability at the time of testing. Comparative herbicide spray treatments showed that the dosage response curve of these cultivars to foliar glufosinate applications was identical (data not shown).

INITIAL GREENHOUSE HERBICIDE TREATMENT. Plants of untransformed cranberry, the transclones, and goldenrod were used for each treatment of 0 or $100 \mathrm{mg} \cdot \mathrm{L}^{-1}$ glufosinate (using the commercial formulation Liberty supplied by Agrevo, Wilmington,
Del.). Herbicide-free Liberty was added to the no-herbicide treatments to make the carrier level the same in both treatments. The plants were sprayed to runoff with a hand sprayer in the late afternoon. The plants were monitored for herbicide effects on growth, leaf chlorosis and leaf and shoot-tip necrosis over the following 4 weeks. Only one transclone was selected for further testing.

COLDFRAME HERBICIDE TREATMENTS OF TRANSFORMED PLANTS. Coldframe-grown plants of untransformed cranberry and the best performing transclone were sprayed in the early morning on rainfree days in midsummer. Plants were sprayed to runoff for each treatment. The first test evaluated glufosinate in $100 \mathrm{mg} \cdot \mathrm{L}^{-1}$ increments up to $500 \mathrm{mg} \cdot \mathrm{L}^{-1}$. Subsequently, glufosinate concentrations up to $1000 \mathrm{mg} \cdot \mathrm{L}^{-1}$ were also evaluated. All treatments, including controls, up to $500 \mathrm{mg} \cdot \mathrm{L}^{-1}$ had a carrier concentration equivalent to $500 \mathrm{mg} \cdot \mathrm{L}^{-1}$, using herbicide-free Liberty to equalize any formulation differences. When higher herbicide levels were tested, the control treatment had a carrier level equivalent to the highest herbicide concentration being tested. The plants were visually evaluated for herbicide injury, and shoot-tip and whole plant survival were recorded. Goldenrod plants were included in all tests to insure that any herbicidal action observed was not unique to cranberry.

GENERATION AND HERBICIDE TREATMENT OF TRANSGENIC PROGENY. Plants of the selected transclone and untransformed plants of 'HyRed' (a high fruit color selection derived from a cross between 'Stevens' and a 'Ben Lear' selection) were allowed to stay in the coldframes until November and then transferred to an unheated greenhouse until January. The plants were then placed in a warm greenhouse under long days (as described above). Upon style emergence, the flowers of the transclone were selfpollinated; alternately, flowers of the transclone and 'HyRed' were emasculated prior to style emergence and reciprocal crosses were performed. Flowering, fruit and seed set, and fruit size of the transclone in the greenhouse were similar to that of untransformed 'Pilgrim'. The resulting first generation seedlings were germinated in vitro and otherwise grown and treated as described above, except that unreplicated individuals were established in 15 $\mathrm{cm}$ standard plastic pots instead of tree bands. These plants were sequentially treated every 2 weeks over the summer with increasing glufosinate levels from 100 to $1000 \mathrm{mg} \cdot \mathrm{L}^{-1}$. The plants were evaluated for herbicide injury and delay in growth. Those plants tolerating the highest glufosinate levels and able to set flower buds were flowered the following winter and self-pollinated as described above to generate an initial set of second generation of seedlings. The selected first generation plants were also cloned as described above and replicated testing for tolerance was performed the following summer at levels up to $8000 \mathrm{mg} \cdot \mathrm{L}^{-1}$.

The second generation seedlings were germinated and cloned in vitro to generate three replicated plants of each individual. These were established in tree bands and herbicide tolerance at 500 and $8000 \mathrm{mg} \cdot \mathrm{L}^{-1}$ evaluated the next summer.

Southern ANALYSis OF TRANSGENIC PROgeny. Total cellular DNA was isolated with a DNeasy Plant Maxi Kit (Qiagen, Valencia, Calif.) from greenhouse leaf tissue of untransformed 'Pilgrim', the original transclone and two selections from the first generation outcrossed progeny demonstrating high herbicide tolerance. DNA from each isolation was divided into two $10-\mu \mathrm{g}$ aliquots and each aliquot digested with either HindIII (single cut site on the plasmid) or NcoI (two cut sites) restriction enzymes. Southern hybridizations were performed using procedures described by Sambrook et al. (1989), and detection as detailed by 


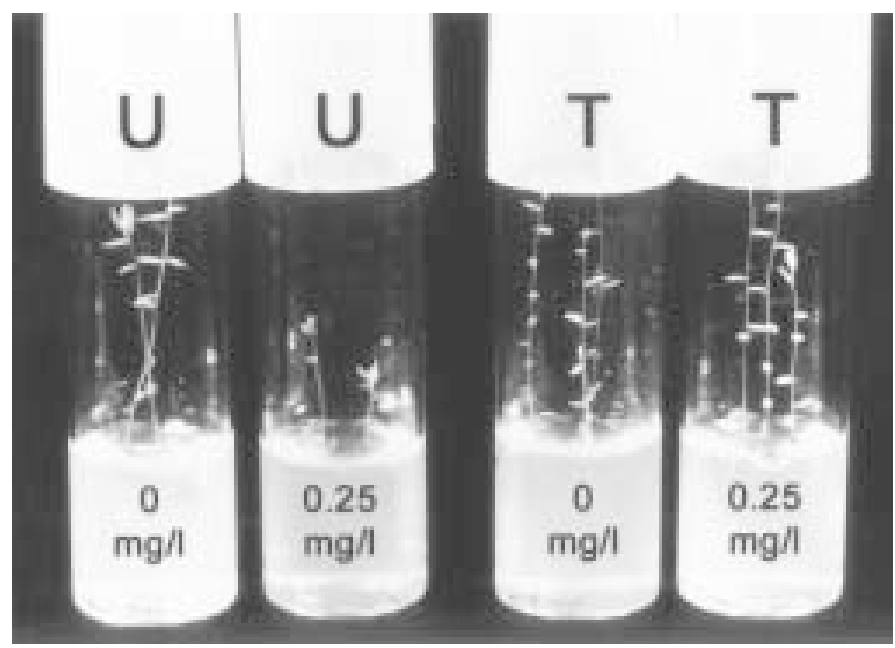

Fig. 1. Shoots of untransformed (U) and transformed (T) cranberry grown for 5 weeks in microculture with and without $0.25 \mathrm{mg} \cdot \mathrm{L}^{-1}$ bialophos added to the medium.

Neuhaus-Url and Neuhaus (1993). Gels were stained with ethidium bromide to verify DNA presence following restriction digests before denaturation, blotting, and probe introduction. The hybridization probe (bar 512 bp) was nonradioactive DIGdATPlabeled using PCR. Each PCR reaction was $50 \mu \mathrm{L}$, consisting of

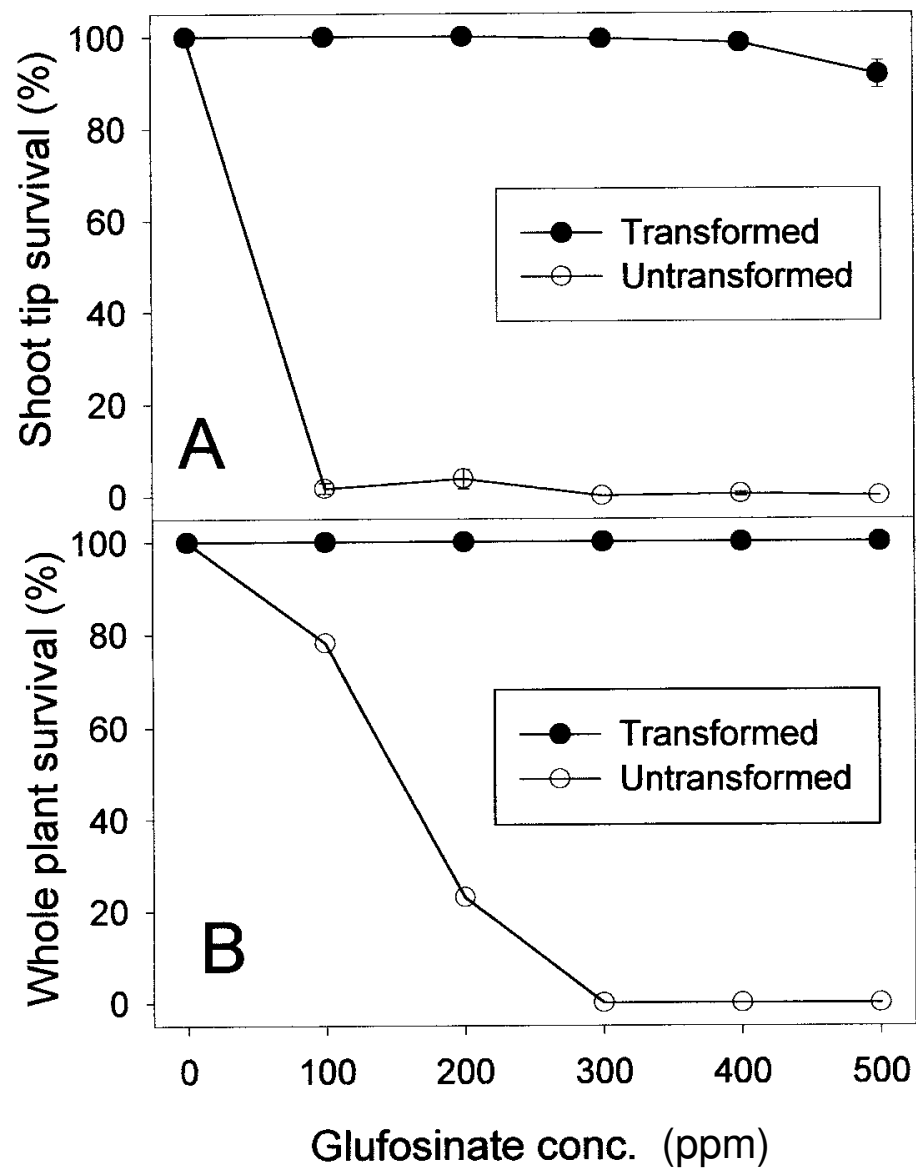

Fig. 2. The response of bar-transformed and untransformed cranberry plants to increasing concentrations of foliar sprays of glufosinate up to $500 \mathrm{mg} \cdot \mathrm{L}^{-1}$. Plants were grown in coldframes and treated in midsummer. (A) The percent of shoot tips surviving 2 weeks after treatment. Values are the mean \pm SE of nine plants. (B) The percent of plants surviving after 4 weeks.
$10 \times$ Expand buffer with $\mathrm{MgCl}_{2}$, DIG probe synthetic mix, Expand Taq, $100 \mathrm{ng}$ plasmid DNA and primers (forward primer nucleotides 4331 to 4354, GCAGGCTGAAGTCCAGCTGCCAG; reverse primer nucleotides 4843 to 4610, TGGTGAGCCCAGACCGACGCCCG).

Statistical analysis. All plants used in a treatment series were grown in the same environment and were the same age. Plants were randomly assigned to treatment groups and during posttreatment evaluation, plants were randomized as to location on the bench or in the coldframe. Three replicate cranberry plants were included in each treatment in the initial greenhouse experiment and nine replicate cranberry plants were included in all other experiments, except as noted above for the screening of seedling plants. For shoot-tip survival, all tips on a plant were examined and an average survival calculated for each replicate plant. The number of shoot tips varied for each plant and ranged from 17 to 53 in the initial comparison between transformed and untransformed plants, and 10 to 16 for the comparison between the original transclone and its selected progeny. Chi-squared analyses of segregation were used to test goodness of fit.

\section{Results and Discussion}

IN VITRO HERBICIDE TOLERANCE. There was little indication of high levels of herbicide tolerance using the in vitro assays. Untransformed shoots were not killed after 5 weeks exposure to levels of up to $20 \mathrm{mg} \cdot \mathrm{L}^{-1}$ bialophos in the medium. However rapid shoot growth (elongation) and the development of adventitious roots were strongly inhibited at levels of $0.1 \mathrm{mg} \cdot \mathrm{L}^{-1}$ and above. The response of the putatively transformed regenerates was variable, however no regenerates grew well in a medium containing $1 \mathrm{mg} \cdot \mathrm{L}^{-1}$ bialophos. The best regenerates grew and developed roots on a medium containing a low level of bialophos $(0.25$ $\mathrm{mg} \cdot \mathrm{L}^{-1}$ ), a concentration that inhibited control shoots (Fig. 1).

The bialophos form of the herbicide was used for in vitro studies because it translocates more readily in shoots than the glufosinate form. Some studies have shown superior results using bialophos as the selective agent (Altpeter et al., 1996; Dennehey et al., 1994). Although direct selection using phosphinothricin agents has been successful for many crops, including woody perennials (Cabrera-Ponce et al., 1995; De Block, 1990), cases where such selection has not been effective also are evident (Bower et al., 1996; De Blondt et al., 1996).

INITIAL GREENHOUSE HERBICIDE TREATMENT. Cranberry plants treated with $100 \mathrm{mg} \cdot \mathrm{L}^{-1}$ glufosinate immediately stopped growth and showed injury to the youngest leaves within a few days. Tip and young leaf necrosis was evident on all plants within 1 week and was followed by extensive necrosis throughout the exposed parts of the treated plants. Plants sprayed with only the carrier continued to grow normally and showed no effects.

The transclones displayed variable amounts of injury. The least injury was observed with one of the 'Pilgrim' transclones where the yellowing and necrosis was restricted to the upper 1 to $2 \mathrm{~cm}$ of the shoots. New growth from axillary buds developed after 1 week. By 4 weeks, all of the plants of this transclone were healthy and little evidence of herbicide injury persisted. All subsequent herbicide trials were conducted using only this 'Pilgrim' transclone (barPg) and its progeny.

No prominent herbicide injury occurred to the goldenrod plants at $100 \mathrm{mg} \cdot \mathrm{L}^{-1}$ Liberty when grown in the greenhouse. A slight distortion of the rapidly growing shoot tips was occasionally observed, but further growth was normal. 


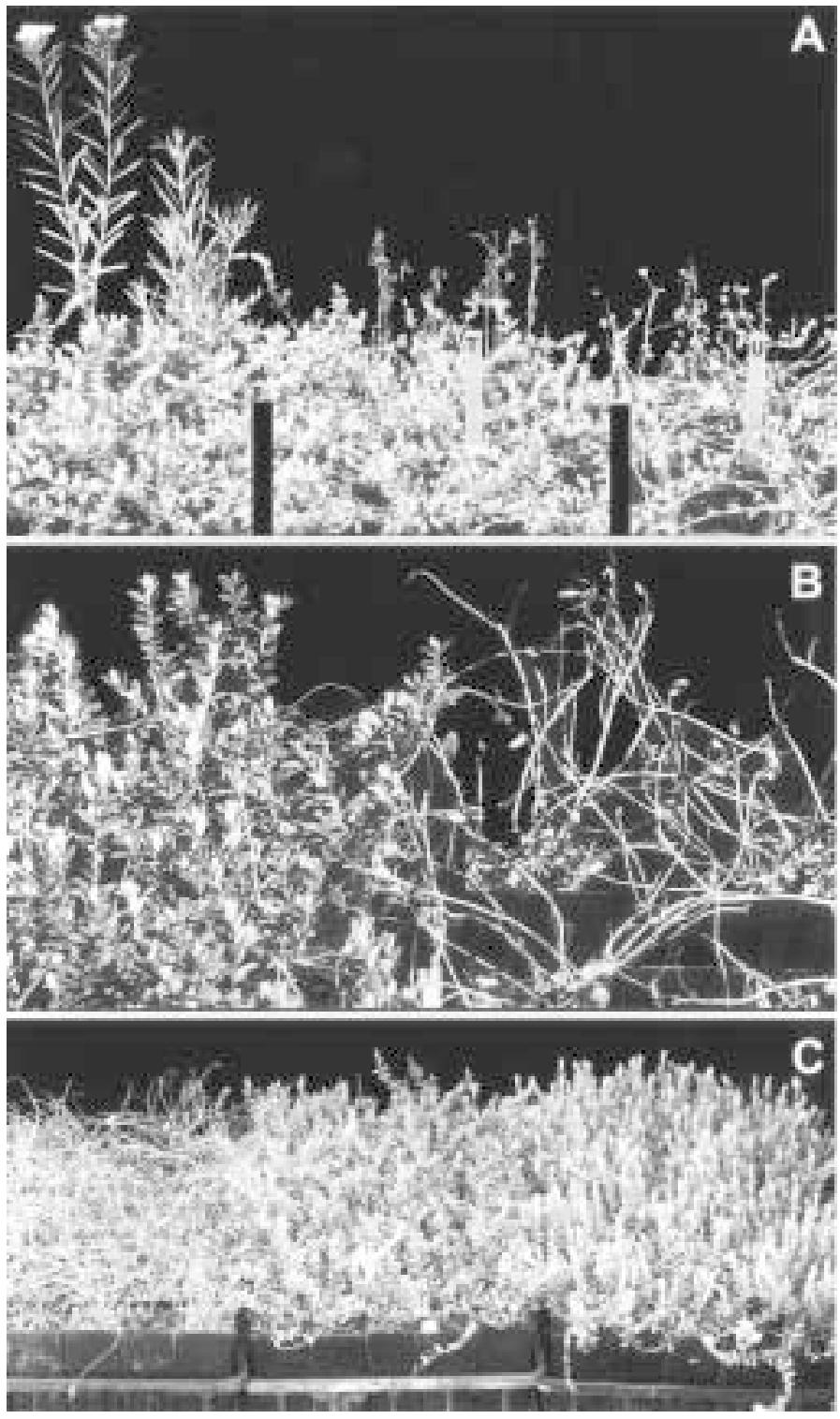

Fig. 3. Effect of glufosinate on bar-transformed and untransformed cranberry plants. (A) Three flats of coldframe-grown cranberry and goldenrod plants subjected to midsummer foliar sprays of glufosinate and photographed 2 weeks after treatment. The left flat contained carrier-only treated plants. The middle flat (T) contained cranberry plants transformed with the bar gene (bar 'Pilgrim') and sprayed with $500 \mathrm{mg} \cdot \mathrm{L}^{-1}$ glufosinate. The cranberry plants remained green while the goldenrod stems and leaves were killed. The right flat (U) contained untransformed cranberry plants sprayed with $500 \mathrm{mg} \cdot \mathrm{L}^{-1}$ glufosinate. All of these plants were killed or very severely injured. (B) Plants of transformed (left) and untransformed cranberry 4 weeks after spraying with $1000 \mathrm{mg} \cdot \mathrm{L}^{-1}$ glufosinate. While the transformed plants suffered some tip injury initially, all plants recovered. None of the untransformed plants survived. (C) Forty plant trays of untransformed (left), transformed ( a ar 'Pilgrim', center), and a highly tolerant 'HyRed' x bar 'Pilgrim' selection 3 weeks after a midsummer spray with 8000 $\mathrm{mg} \cdot \mathrm{L}^{-1}$ glufosinate. Only the tips of the parent bar 'Pilgrim' were killed, whereas the untransformed plants were totally killed. The 'HyRed' $\mathrm{x}$ bar 'Pilgrim' selection showed no shoot tip death and only a brief delay in growth.
The initial conclusion from these greenhouse tests was that there was insufficient tolerance in the transformed plants to make this method of weed control commercially practical. Goldenrod grows similarly in both the greenhouse and the field. Cranberry, on the other hand, is far more succulent in the greenhouse, particularly under high nitrogen fertilization. Under field conditions, the growth is slower, the leaves smaller, and tissue less succulent. Sankula et al. (1997) reported that herbicide tolerance of bar-transformed rice was greater in more developed than lessdeveloped (younger) plants, indicating that tissue quality is an important factor when evaluating glufosinate tolerance. Other researchers have found that evaluation of herbicide tolerance differs between field and greenhouse/laboratory conditions (D'Halluin et al., 1990; Garrod, 1989). Thus it was decided to further evaluate the herbicide tolerance under conditions more typical of cranberry field beds. The growth of cranberry plants grown in coldframes more closely resembles that of field-grown plants, and thus further evaluations were conducted in coldframes.

COLDFRAME HERBICIDE TREATMENTS OF TRANSFORMED PLANTS. Vegetative growth and vigor of the transformed and untransformed plants in the coldframe were equivalent, and were significantly less succulent than greenhouse plants. All transformed and untransformed coldframe plants from $500 \mathrm{mg} \cdot \mathrm{L}^{-1}$ equivalent carrier-only treatments continued to grow and showed no effects of the spray.

The initial coldframe trial revealed a greater differential in the herbicide effects between transformed and untransformed cranberry plants than that previously observed in the greenhouse. Levels as low as $100 \mathrm{mg} \cdot \mathrm{L}^{-1}$ glufosinate killed the vast majority of untransformed cranberry shoot tips within 2 weeks (Fig. 2A). Plant mortality at 4 weeks escalated with increasing herbicide concentrations up to $300 \mathrm{mg} \cdot \mathrm{L}^{-1}$, where none of the untransformed plants survived (Fig. 2B). Conversely, no plants of the transformed barPg were killed by any herbicide concentration tested (Figs. 2B and 3A), and shoot-tip survival was affected only above levels of $400 \mathrm{mg} \cdot \mathrm{L}^{-1}$ (Fig. 2A). There was a delay in growth of barPg plants up to 2 weeks and some irreversible injury to the young leaves at the higher herbicide levels. However, all these plants were healthy and actively growing by 4 weeks after spraying (Fig. 3A).

Injury to goldenrod plants also escalated with the level of herbicide treatment (data not shown). At $200 \mathrm{mg} \cdot \mathrm{L}^{-1}$, the leaf tips were injured, but the plants initiated new growth within 2 weeks. At $300 \mathrm{mg} \cdot \mathrm{L}^{-1}$, all shoot tips were killed, but new growth developed from the lower stems. At $400 \mathrm{mg} \cdot \mathrm{L}^{-1}$, most of the aboveground portions of the plants were killed. Carrier-only treated plants continued to grow and flower (Fig. 3A). The roots and rhizomes of goldenrod were not killed by any herbicide level. Sedge plants grown in the coldframes were injured by $100 \mathrm{mg} \cdot \mathrm{L}^{-1}$ and were capable of regrowing from basal parts; $400 \mathrm{mg} \cdot \mathrm{L}^{-1}$ treatments killed sedge plants.

The above results confirmed that these coldframe transgenic plants were considerably more tolerant to glufosinate than shoots grown under greenhouse conditions. To further determine the

Table 1. Chi squared analysis of herbicide tolerance segregation in selfed and outcrossed transgenic cranberry progeny.

\begin{tabular}{lcccc}
\hline \hline Cross & $\begin{array}{c}\text { Progeny } \\
\text { tested }\end{array}$ & $\begin{array}{c}\text { Tolerant } \\
\text { progeny }\end{array}$ & $\begin{array}{c}\text { Susceptible } \\
\text { progeny }\end{array}$ & $\begin{array}{c}\text { Ratio } \\
\text { tested }\end{array}$ \\
\hline bar 'Pilgrim' x self & 88 & 50 & 38 & $3: 1$ \\
bar 'Pilgrim' x 'HyRed' & 94 & 50 & 44 & $1: 1$ \\
'HyRed' x bar 'Pilgrim' & 52 & 21 & 31 & $1: 1$ \\
\hline
\end{tabular}

\footnotetext{
NS, ${ }^{* * *}$ Nonsignificant or significant at $P<0.01$, respectively.
} 
level of tolerance achieved, a second test with higher glufosinate concentrations (up to $1000 \mathrm{mg} \cdot \mathrm{L}^{-1}$ ) was performed. While there was some increase in shoot tip injury, all the transformed plants survived and had resumed active growth by 4 weeks (Fig. 3B), while the herbicide-treated untransformed plants were killed.

Coldframe herbicide treatments of barPg PRogeny. The bar gene was successfully transferred to both self-pollinated and outcrossed progeny, based on the ability to tolerate at least 100 $\mathrm{mg} \cdot \mathrm{L}^{-1}$ glufosinate. Cranberry is a diploid species, and when barPg was crossed to the untransformed 'HyRed', the number of tolerant to susceptible progeny agreed with the expected $1: 1$ ratio for a single insertion site (Table 1). However, the selfed population was below the expected 3:1 ratio. Most of the tolerant progeny demonstrated a level of tolerance similar to that of the barPg parent, based on sprays with escalating glufosinate concentration. Some outcrossed individuals were more tolerant than the barPg parent, as they showed no tip death or delay in growth at $1000 \mathrm{mg} \cdot \mathrm{L}^{-1}$ glufosinate. For further evaluation, replicated plants were initially screened in the greenhouse (data not shown) and two individuals from the outcrossed progeny (one 'HyRed' $\mathrm{x}$ barPg and one barPg x 'HyRed') were selected for replicated testing in the coldframe. The two selected progeny were able to tolerate high levels of glufosinate, up to $4000 \mathrm{mg} \cdot \mathrm{L}^{-1}$, without significant shoot tip necrosis (Fig. 4). A subsequent bulk test using groups of forty plants confirmed the ability of one of these selections to tolerate $8000 \mathrm{mg} \cdot \mathrm{L}^{-1}$ with only minimal delay in growth (Fig. 3C).

One explanation for the elevated herbicide tolerance in some of the progeny is a reduction in transgene copy number or other rearrangements in the inserted genes that would favor enhanced gene expression. For further evaluation, Southern analysis was performed on these individuals. The results indicated that multiple copies of the bar gene were stably inserted, as a band equivalent in size to the whole plasmid (5511 base pairs) was recovered with HindIII digestion, in addition to two smaller bands (likely fragments produced from the outlying plasmid ends to restriction sites within the plant genome) (Fig. 5). Similar results were obtained in a previous Southern probing for CaMV

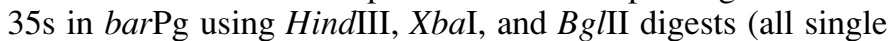
restriction sites on the plasmid, data not shown). The NcoI

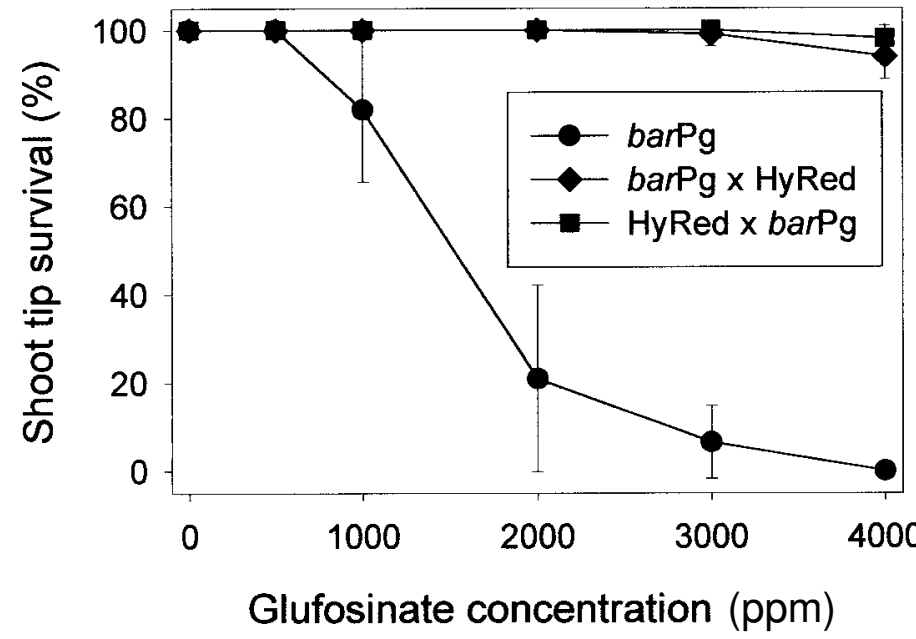

Fig. 4. The survival of shoot tips of transformed 'Pilgrim' cranberry (bar $\mathrm{Pg}$ ) and two selected progeny (one bar 'Pilgrim' $\mathrm{x}$ 'HyRed' and one 'HyRed' $\mathrm{x}$ bar 'Pilgrim') to increasing concentrations of foliar sprays of glufosinate up to 4000 $\mathrm{mg} \cdot \mathrm{L}^{-1}$. Plants were grown and tested in coldframes in midsummer. Values are the mean \pm SE of nine plants. digestion (Fig. 5) supports multiple copies as well since the expected plasmid-only fragments $(\approx 3700$ and 1800 base pairs) were observed, with two additional bands like the others. Because only two nonplasmid bands were produced in each digest, the Southerns indicate a single insertion site. There was no difference in the banding pattern between the higher tolerant selections and the barPg parent, suggesting that the difference in tolerance was not due to rearrangement of the inserted genes. As expected, untransformed 'Pilgrim' showed no hybridization signal.

Two other explanations for enhanced herbicide tolerance in the selected progeny are an interaction with other factors in the native genome (such as elevated glutamine synthetase levels) or a repositioning of the inserted genes to a higher expressing area. Analysis of the phospinothricin acetyl transferase and glutamine synthetase enzyme activities would be required to begin to address such hypotheses. However, a clear explanation for the observed enhanced tolerance in the progeny is not obvious.

INITIAL EVALUATION OF SECOND GENERATION PROGENY. While the majority of the barPg selfed progeny were tolerant, the number of tolerant individuals was less than expected. Gene silencing may be one explanation. A variety of plant systems have shown significant levels of transgene silencing (Iyer et al., 2000; Kumar and Fladung, 2001; Morel et al., 2000). In lettuce, increasing levels of transgene silencing were observed with successive generations when the CaMV 35s promoter was used (McCabe et al., 1999). In our studies with cranberry, a limited test of 39 second generation seedlings (derived from self-pollinating the two highly herbicide-tolerant first generation progeny selections) was conducted using replicated testing at $500 \mathrm{mg} \cdot \mathrm{L}^{-1}$. No indica-

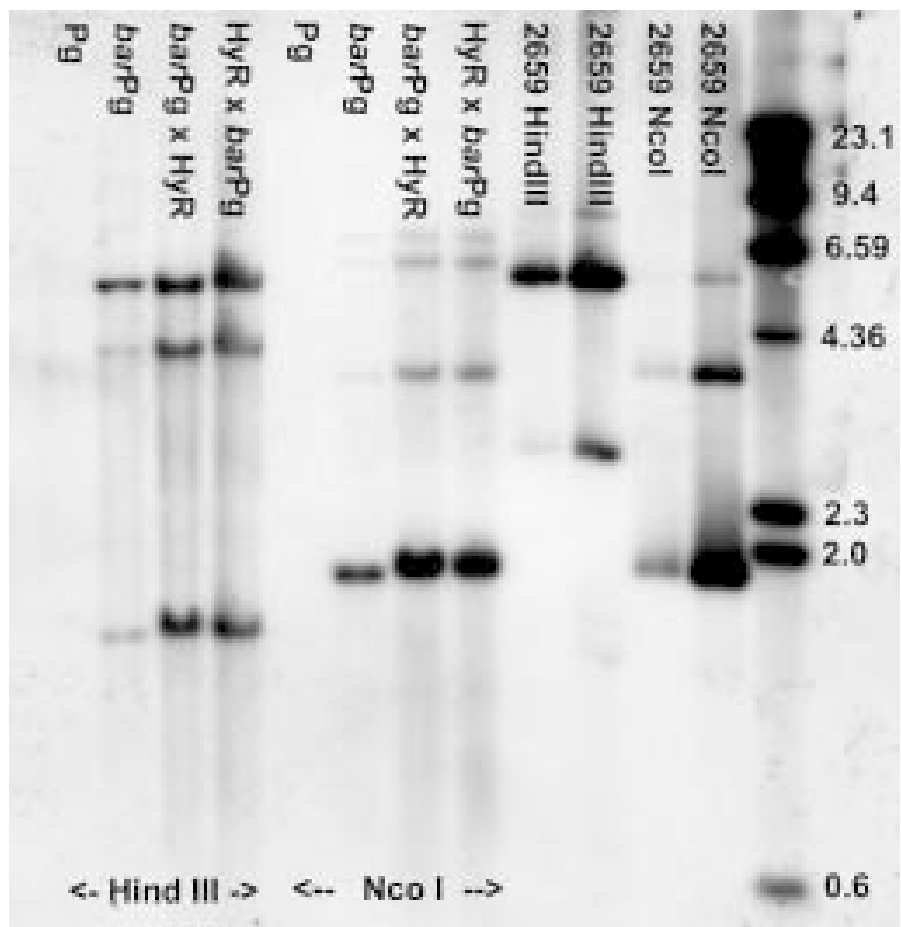

Fig. 5. Autoradiogram from hybridization of bar to untransformed 'Pilgrim' cranberry (Pg), bar-transformed 'Pilgrim' (bar $\mathrm{Pg}$ ) and two selections from outcrossed progeny with high herbicide tolerance (one barPg X 'HyRed' and one 'HyRed' $\mathrm{x}$ barPg). The DNA from these samples was cut with two restriction enzymes, HindIII (left) or $N c o$ I (center) and compared to the original source plasmid (2659, HindIII or NcoI as indicated). Molecular weight markers are indicated on the right. The fragments suggest the presence of multiple copies of the bar gene at a single site in the original transformant and no rearrangements in the selected progeny. 
tion of gene silencing was observed in this population, as a ratio close to the expected 3:1 tolerant to susceptible was observed (25 tolerant and 9 susceptible). In addition, when tested at $8000 \mathrm{mg} \cdot \mathrm{L}^{-}$ ${ }^{1}$, a majority (17) of the tolerant second generation progeny displayed the high tolerance (no shoot tip necrosis) of their parents.

STRATEGIES FOR THE USE OF HERBICIDE TOLERANT CRANBERRIES. These results demonstrate the feasibility of successfully transforming cranberry for the expression of an introduced herbicide tolerance gene. Expression of the introduced gene in coldframe plants has been stable over multiple seasons after the initial transformation. The introduced trait has been successfully transferred to two generations of progeny, with enhanced levels of tolerance evident in selected outcrossed progeny.

The definitive timing and dosage of herbicide applications will eventually have to be established under actual field conditions. An important time for cranberry growers to control weeds is early in the life of a bed, when cranberry vines are becoming established and are more susceptible to competition from weeds. Established and well-maintained cranberry beds are very competitive and thus invasion by weeds is slow. The use of an herbicide such as Liberty may be most intensive during the first 5 years after planting a bed. After establishment, only periodic use in specific weed-infested areas would be warranted, thus helping to avoid residue and weed resistance problems. Any resistant weeds that might develop could still be controlled using glyphosate wiping, which the growers currently use.

\section{Literature Cited}

Altpeter, F., V. Vasil, V. Srivastava, E. Stoger, and I.K. Vasil. 1996. Accelerated production of transgenic wheat (Triticum aestivum L.) plants. Plant Cell Rpt. 16:12-17.

Berry-Lowe, S.L., T.D. McKnight, D.M. Shah, and R.B. Meagher. 1982. The nucleotide sequence, expression, and evolution of one member of a multigene family encoding the small subunit of ribulose 1,5bisphosphate carboxylase in soybean. J. Mol. Appl. Genet. 1:483-489.

Bower, R., A.R. Elliott, B.A.M. Potier, and R.G. Birch. 1996. High efficiency, microprojectile-mediated cotransformation of sugarcane, using visible or selectable markers. Mol. Breeding 2:239-249.

Cabrera-Ponce, J.L., G. Vegas-Garcia, and L. Herrera-Estrella. 1995. Herbicide resistant transgenic papaya plants produced by an efficient particle bombardment transformation method. Plant Cell Rep.15:1-7.

Dana, M.N. 1989. The American cranberry industry. Acta. Hortic. 241:287-294.

De Block, M. 1990. Factors influencing the tissue culture and the Agrobacterium tumefaciens-mediated transformation of hybrid aspen and poplar clones. Plant Physiol. 93:1110-1116.

De Bondt, A., K. Eggermont, I. Penninckx, I. Goderis, and W.F. Broekaert. 1996. Agrobacterium-mediated transformation of apple (Malus $\times$ domestica Borkh.): An assessment of factors affecting regeneration of transgenic plants. Plant Cell Rpt. 15:549-554.

Dennehey, B.K., W.L. Petersen, C. Ford-Santino, M. Pajeau, and C.L. Armstrong. 1994. Comparison of selective agents for use with the selectable marker gene bar in maize transformation. Plant Cell Tissue Organ Cult. 36:1-7.

D'Halluin, K., J. Botterman, and W. de Greef. 1990. Engineering of herbicide-resistant alfalfa and evaluation under field conditions. Crop Sci. 30:866-871.

Garrod, J.F. 1989. Comparative responses of laboratory and field grown test plants to herbicides. Aspects Appl. Biol. 21:51-64.

Gehrke, L., P.E. Auron, G.J. Quigley, A. Rich, and N. Sonenberg. 1983. 5'-Conformation of capped alfalfa mosaic virus ribonucleic acid 4 may reflect its independence of the cap structure or of cap-binding protein for efficient translation. Biochemistry 22:5157-5164.

Iyer, L.M., S.P. Kumpatla, M.B. Chandrasekharan, and T.C. Hall. 2000. Transgene silencing in monocots. Plant Mol. Biol. 43:323-346.

Kumar, S., and M. Fladung. 2001. Gene stability in transgenic aspen (Populus). II. Molecular characterization of variable expression of transgene in wild and hybrid aspen. Planta 213:731-740.

Leason, M., D. Cunliffe, D. Parkin, P.J. Lea, and B. Miflin. 1982. Inhibition of pea glutamine synthetase by methione sulphoximine, phosphinithricin and other glutamate analogues. Phytochemistry 21:855-857.

McCabe, M.S., F. Schepers, A. van der Arend, U. Mohapatra, A.M.M. de Laat, J.B. Power, and M.R. Davey. 1999. Increased stable inheritance of herbicide resistance in transgenic lettuce carrying a petE promoter-bar gene compared with a CaMV 35S-bar gene. Theor. Appl. Genet. 99(3-4):587-592.

McCown, B.H., D.E. McCabe, D.R. Russell, D.J. Robinson, K.A. Barton, and K.F. Raffa. 1991. Stable transformation of Populus and incorporation of pest resistance by electric discharge particle bombardment. Plant Cell Rep. 9:590-594.

Morel, J.B., P. Mourrain, C. Beclin, and H. Vaucheret. 2000. DNA methylation and chromatin structure affect transcriptional and posttranscriptional transgene silencing in Arabidopsis. Current Biol. 10:1591-1594.

Nagy, F., J.T. O’Dell, G. Morelli, and N.H. Chua. 1985. Properties of expression of the $35 \mathrm{~S}$ promoter from CaMV in transgenic tobacco plants. In: M. Zaitlin, P. Day, and A. Hollaender (eds.) Biotechnology in plant sciences: Relevance to agriculture in the eighties, p. 227-235. Academic Press, N.Y.

Neuhaus-Url, G., and G. Neuhaus. 1993. The use of the nonradioactive digoxigenin chemiluminescent technology for plant genomic southern blot hybridization: A comparison with radioactivity. Transgenic Res. 2:115-120.

Odell, J.T., F. Nagy, and N.H. Chua. 1985. Identification of DNA sequences required for activity of the cauliflower mosaic virus $35 \mathrm{~S}$ promoter. Nature 313:810-812.

Patten, K.D., and J. Wang. 1994. Cranberry yield and fruit quality reduction caused by weed competition. HortScience 29:1127-1130.

Sambrook, J., E.F. Fritsch and T. Maniatis. 1989. Molecular cloning: a laboratory manual. 2nd ed. Cold Spring Harbor, New York.

Sankula, S., M.P. Braverman, and S.D. Linscombe. 1997. Response of BAR-transformed rice (Oryza sativa) and red rice (Oryza sativa) to glufosinate application timing. Weed Tech. 11:303-307.

Serres, R.A., B.H. McCown, E.L. Zeldin, E.J. Stang, and D.E. McCabe. 1993. Applications of biotechnology to cranberry: a model for fruit crop improvement. Acta Hortic. 345:149-156.

Serres, R., E. Stang, D. McCabe, D. Russell, D. Mahr, and B. McCown. 1992. Gene transfer using electric discharge particle bombardment and recovery of transformed cranberry plants. J. Amer. Soc. Hort. Sci. 117:174-180.

Thompson, C.J., N.R. Movva, R. Tizard, R. Crameri, J.E. Davies, M. Lauwereys, and J. Botterman. 1987. Characterization of the herbicideresistance gene bar from Streptomyces hygroscopicus. EMBO J. 6:2519-2523.

Wallsgrove, R.M., J.C. Turner, N.P. Hall, A.C. Kendall, and S.W.J. Bright. 1987. Barley mutants lacking chloroplast glutamine synthetaseBiochemical and genetic analysis. Plant Physiol. 83: 155-158.

Wild, A., and R. Manderscheid. 1984. The effect of phosphinothricin on the assimilation of ammonia in plants. Z. Naturforsch. 39:500-504.

Wild, A., H. Sauer, and W. Ruehle. 1987. The effect of phosphinothricin (glufosinate) on photosynthesis: I. Inhibition of photosynthesis and accumulation of ammonia. Z. Naturforsch. 42:263-269.

Yanisch-Perron, C., J. Vieira, and J. Messing. 1985. Improved M13 phage cloning vectors and host strains: nucleotide sequences of the M13mp18 and pUC19 vectors. Gene 33:103-119. 